\title{
Interleukin-22 regulates the homeostasis of the intestinal epithelium during inflammation
}

\author{
XINYAN ZHANG ${ }^{12^{*}}$, SHIJIE LIU ${ }^{2 *}$, YUEQIAN WANG ${ }^{3 *}$, HUIQIONG HU ${ }^{4}$, LIANG LI $^{2}$, \\ YIBIN WU ${ }^{3}$, DUO CAO ${ }^{5}$, YUANKUN CAI ${ }^{3}$, JIQIN ZHANG ${ }^{2}$ and XUELI ZHANG ${ }^{4}$ \\ ${ }^{1}$ Hospital and Institute of Obstetrics and Gynecology Affiliated to Fudan University, Shanghai 200011; \\ ${ }^{2}$ East China Normal University and Shanghai Fengxian District Central Hospital Joint Center for Translational Medicine, \\ Shanghai Key Laboratory of Regulatory Biology, School of Life Sciences, East China Normal University, \\ Shanghai 200241; ${ }^{3}$ Shanghai The Fifth People's Hospital Affiliated to Fudan University, Shanghai 200240; \\ ${ }^{4}$ Southern Medical University Affiliated Fengxian Hospital, Shanghai 201499; \\ ${ }^{5}$ College of Life Sciences, Northwest University, Xi'an, Shanxi 710069, P.R. China
}

Received July 9, 2018; Accepted January 30, 2019

DOI: $10.3892 /$ ijmm.2019.4092

\begin{abstract}
Interleukin-22 (IL-22) has both pro-inflammatory and anti-inflammatory properties in a number tissues depending on the environment. Epithelial cells usually have a rapid turnover and are fueled by tissue stem cells. However, the question of whether IL-22 regulates tissue homeostasis through the modulation of stem cells remains unanswered. In this study, we investigated the role of IL-22 in the homeostasis of intestinal epithelial cells (IECs) during inflammation through a 3D organoid culture system. qPCR was performed to detect the changes in important gene transcriptions, and immunohistochemistry and western blot analysis were carried out to determine protein expression. As a result, we found that the expression of IL-22 was synchronously altered with the damage of the intestine. IL-22 treatment promoted cell proliferation and suppressed the cell differentiation of intestinal organoids. Surprisingly, IL-22 also led to self-renewal defects of intestinal stem cells (ISCs), thereby eventually resulting in the death of organoids. In examining the underlying mechanisms, we found that IL-22 activated signal transducer and activator
\end{abstract}

Correspondence to: Dr Jiqin Zhang, East China Normal University and Shanghai Fengxian District Central Hospital Joint Center for Translational Medicine, Shanghai Key Laboratory of Regulatory Biology, School of Life Sciences, East China Normal University, 500 Dongchuan Road, Shanghai 200241, P.R. China

E-mail: jqzhang@bio.ecnu.edu.cn

Dr Xueli Zhang, Southern Medical University Affiliated Fengxian Hospital, 6600 Nan Feng Road, Shanghai 201499, P.R. China

E-mail: lejing1996@aliyun.com

*Contributed equally

Key words: interleukin-22, intestinal epithelium, inflammation, organoid, cell proliferation, cell differentiation, Wnt pathway of transcription 3 (Stat3) phosphorylation and suppressed the Wnt and Notch signaling pathways. Importantly, Wnt3a treatment attenuated the organoid defects caused by IL-22, which consolidated the importance of Wnt pathway at the downstream of IL-22. Collectively, the findings of this study indicate that IL-22 regulates the homeostasis of the intestinal epithelium and is critical for the regeneration of the intestine during inflammation. Thus, the data of this study may provide a potential strategy and a basis for the treatment of diseases of intestinal inflammation in clinical practice.

\section{Introduction}

The intestinal epithelium forms a physical barrier that separates the luminal contents of the gut from the internal milieu (1). Intestinal epithelial cells (IECs) also perform several other functions, such as the sampling of the intestinal microenvironment, the sensing of both beneficial and harmful microbes and the secretion of numerous factors in response to positive or negative signals, which are crucial for intestinal homeostasis (2). To fulfill these diverse functions, the intestinal epithelium has unique anatomical and cellular adaptations, and IECs comprise several specialized cell types with distinct function $(2,3)$. The dynamic crosstalk between IECs and local immune cells represents one of the basic features of intestinal homeostasis $(2,3)$. These interactions are not only essential for maintaining homeostasis, but are also critical for the pathogenesis of inflammatory bowel disease (IBD) and intestinal epithelium restitution following injury.

Interleukin (IL)-22 belongs to the IL-10 cytokine family and is expressed by several types of lymphocytes, including $\mathrm{CD}^{+}{ }^{+} \mathrm{T}$ cells, Th17 cells, natural killer (NK) cells and neutrophils (4-14). IL-22 binds to a heterodimeric receptor consisting of IL-22RA1 and IL10-RB. In contrast to the wide expression pattern of IL-10RB, IL-22RA1 is expressed by non-hematopoietic cells, such as epithelial cells of the gastrointestinal tract and skin (15-17). Thus, IL-22 can function in both lymphocytes and epithelial cells. In the intestine, IL-22 has been 
shown to prevent prolonged inflammation in models of dextran sodium sulfate (DSS)-mediated colitis and graft versus host disease $(13,18,19)$. On the contrary, IL-22 can induce inflammatory responses in the other intestine models (20). These findings indicate that IL-22 has dual functions of promoting and antagonizing inflammation, which likely depends on the specific context. To date, these complex roles of IL-22 are not yet fully understood.

It is well known that intestinal stem cells (ISCs) are located at the crypt base and specifically express markers, such as leucine-rich repeat-containing $\mathrm{G}$-protein coupled receptor 5 (Lgr5) (21). They play significant roles in intestinal homeostasis and regeneration. An ex vivo 3D culture system of intestinal organoids (epithelial mini-guts), highly mimicking the growth in vivo, has been successfully established by Clever's laboratory. This was done by culturing intestinal epithelial organoids in Matrigel and supplementing epidermal growth factor (EGF), activators of the Wnt and Notch pathways, and an inhibitor of the bone morphogenetic protein (BMP) pathway (22). This powerful system has been widely used for the study of intestinal epithelium homeostasis (22-26).

In this study, we applied DSS and X-ray induced colitis mouse models, and an ex vivo organoid culture system to explore the role of IL-22 in regulating the homeostasis of the intestinal epithelium during inflammation. We found that IL-22 was dynamically expressed with the development of intestinal inflammation. IL-22 promoted cell proliferation, but inhibited the differentiation of intestinal organoids. It also suppressed the self-renewal capacity of ISCs and accordingly resulted in the destruction of organoids. Mechanistically, IL-22 activated signal transducer and activator of transcription 3 (Stat3) activity, but suppressed the Wnt and Notch signaling pathways, in which the change in Wnt signaling was more dominant.

\section{Materials and methods}

Ethics statement. All animal experiments conformed to the regulations drafted by the Association for Assessment and Accreditation of Laboratory Animal Care in Shanghai and were approved by the East China Normal University Center for Animal Research.

Animal experiments. For the model of IBD, a total of 35 male ( $\mathrm{n}=5 /$ group) C57BL/6 mice ( 8 weeks old, weighing approximately $20 \mathrm{~g}$ ) were obtained from Shanghai SLAC Laboratory Animal Co., Ltd. (Shanghai, China) and maintained under SPF experimental animal conditions (temperature, $23 \pm 2^{\circ} \mathrm{C}$; humidity, $65 \pm 5 \%$ ) in a 12 -h light/dark cycle and fed a standard laboratory diet and water in East China Normal University Center for Animal Research. Acute colitis was induced at day 0 by the administration of $2.5 \%(\mathrm{w} / \mathrm{v})$ DSS (molecular weight, 36-50 kDa; MP Biomedicals, Santa Ana, CA, USA) in their drinking water and this was then changed to normal drinking water at day 5 . The mice were sacrificed at different time points as indicated (days 0, 2, 4, 6, 8, 10 and 12) and intestinal samples were collected for RNA extraction or histological analysis.

For in vivo regeneration assay, a total of 20 male ( $n=5 /$ group) C57BL/6 mice (8 weeks old, weighing approximately $20 \mathrm{~g}$ ) were obtained from Shanghai SLAC Laboratory Animal Co., Ltd. and kept under SPF experimental animal conditions (temperature, $23 \pm 2{ }^{\circ} \mathrm{C}$; humidity, $65 \pm 5 \%$ ) in a 12 -h light/dark cycle and fed a standard laboratory diet and water in East China Normal University Center for Animal Research. The mice were irradiated by 9.0 Gy X-ray using a Biological X-ray irradiator (RS 2000 series; Rad Source Technologies, Inc., Suwanee, GA, USA) operated at $250 \mathrm{kVp}, 15 \mathrm{~mA}$. The mice were sacrificed every other day after irradiation by cervical dislocation.

Organoid culture. Small intestinal crypt isolation and culture were performed as previously described $(21,22)$. Briefly, the small intestine was washed in cold PBS. The tissue was then chopped into approximately 3-5-mm-thick sections, washed with cold PBS and incubated in $5 \mathrm{mM}$ EDTA in PBS for $30 \mathrm{~min}$ on ice. The tissue fragments were suspended vigorously, and the supernatants, including most of the villi were discarded. The sediment was further resuspended with cold PBS; the yielded supernatants enriched in crypts were collected and filter through a $70 \mu \mathrm{m}$ cell mesh (BD Biosciences, San Jose, CA, USA). The crypts were then pelleted by centrifugation (132 x g, 5 min), suspended in ADF medium (advanced DMEM F12) (Thermo Fisher Scientific, Waltham, MA, USA) containing 1\% GlutaMAX (Thermo Fisher Scientific). The crypts were centrifuged at low speed ( $33 \mathrm{x}$ g, $3 \mathrm{~min})$ for 2-3 times to remove single cells. The final crypts were resuspended with growth factor reduced to Matrigel (356231; BD Biosciences) at 5-10 crypts per $\mu 1$, followed by seeding on a 96 -well plate $(5 \mu 1$ per well) or 48 -well plate $(30 \mu 1$ per well). Culture medium was made by ADF supplemented with penicillin/streptomycin, $10 \mathrm{mM}$ HEPES, 1X GlutaMAX, $1 \mathrm{X}$ N2, 1X B27 (all from Thermo Fisher Scientific) and $1 \mu \mathrm{M}$ $\mathrm{N}$-acetylcysteine (Sigma-Aldrich; Merck KGaA, Darmstadt, Germany) containing $50 \mathrm{ng} / \mathrm{ml}$ Murine EGF, $100 \mathrm{ng} / \mathrm{ml}$ Murine Noggin and $1 \mu \mathrm{g} / \mathrm{ml}$ Human R-spondin-1 (all from PeproTech, Rocky Hill, NJ, USA). The medium was changed every other day.

For single cell culture, 4-6-day cultured organoids were dissociated with TrypLE express (Thermo Fisher Scientific) including 2,000 U/ml DNase (Roche Diagnostics, Indianapolis, IN, USA) for $10 \mathrm{~min}$ at $37^{\circ} \mathrm{C}$. Dissociated cells were passed through a $20 \mu \mathrm{m}$ cell mesh (BD Biosciences) and embedded in Martrigel containing $1 \mu \mathrm{M}$ jag1 (AnaSpec, Fremont, CA, USA) at up to 5,000-10,000 cells per 30-50 $\mu \mathrm{l}$. The culture medium was regular organoid culture medium supplemented with $10 \mu \mathrm{M}$ ROCK inhibitor Y27632 (Sigma-Aldrich; Merck KGaA).

For rescue experiments, $100 \mathrm{ng} / \mathrm{ml}$ IL-22 (R\&D Systems, Minneapolis, MN, USA), $200 \mathrm{ng} / \mathrm{ml}$ Wnt3a (R\&D Systems), $1 \mu \mathrm{M}$ Jag1 (AnaSpec), $5 \mu \mathrm{M}$ WP1066 (Stat3 inhibitor; Santa Cruz Biotechnology, Inc., Dallas, TX, USA), $3 \mu \mathrm{M}$ Stattic (Stat3 inhibitor; Santa Cruz Biotechnology, Inc.,) were used at different combinations in oranoid culture medium: Vehicle (without IL22), Stattic, WP1066, Wnt3a, Jag1, IL-22, IL-22 plus Stattic, IL-22 plus WP1066, IL-22 plus Wnt3a, IL-22 plus Jag1.

Reverse transcription-quantitative PCR (RT-qPCR). RNA from the organoids, intestines (IECs) and immune cells [macrophages, monocytes, $\mathrm{CD} 4^{+} \mathrm{T}$ cells and dendritic cells (DCs) were sorted from mouse peripheral blood by corresponding magnetic beads; Miltenyi Biotec, Bergisch Gladbach, 
Germany] was obtained by tissue homogenization using TRIzol reagent (Takara Bio, Inc., Otsu, Japan), followed by RNA precipitation in isopropanol, resuspension in DEPC-treated water and verification as DNA free by PCR. cDNA was synthesized with the Superscript RNase H2 Reverse Transcriptase kit (Takara Bio, Inc.) using $2.5 \mathrm{mM}$ random hexamers (Takara Bio, Inc.). Quantitative (real-time) PCR (qPCR) was performed using the SYBR-Green PCR kit (Takara Bio, Inc.) on a Mx3005P thermal cycler (Stratagene, San Diego, CA, USA). The amplification conditions included 3 processes, namely hold stage $\left(1\right.$ cycle): $95^{\circ} \mathrm{C}$ for $1 \mathrm{~min}$; PCR stage (40 cycles): $95^{\circ} \mathrm{C}$ for $5 \mathrm{sec}, 55^{\circ} \mathrm{C}$ for $30 \mathrm{sec}$; melt curve stage ( 1 cycle): $95^{\circ} \mathrm{C}$ for $5 \mathrm{sec}, 55^{\circ} \mathrm{C}$ for $30 \mathrm{sec}$ and $95^{\circ} \mathrm{C}$ for $30 \mathrm{sec}$. The sequences of the main primers were as follows: $\beta$-actin sense, CAGCCTTCCTTCTTGGGTAT and antisense, TGATCTTGATCTTCATGGTGC; $I l-22$ sense, ACATCG TCAACCGCACCTTT and antisense, CAGCCTTCTGAC ATTCTTCTGGAT; $I l$-22ral sense, CTACGTGTGCCGAGT GAAGA and antisense, GGTAGGTTGCAGGATGGAGA; Il-10rb sense, TTCGGAGTGGGTCAATGTCA and antisense, GACCTCAGAGTCGTACGGAG; Lgr5 sense, CCTACTCGA AGACTTACCCAGT and antisense, GCATTGGGGTGA ATGATAGCA; olfactomedin 4 (Olfm4) sense, TCTTGGGCA GAAGGTGGGACT and antisense, GGACCGTCAGGTTCA GGAGC; achaete-scute family bHLH transcription factor 2 (Ascl2) sense, AAGCACACCTTGACTGGTACG; and antisense, AAGTGGACGTTTGCACCTTCA; zinc and ring finger 3 (Znrf3) sense, CCAGTGGTGTATGTGAAGGGTG and antisense, AATTCTGACTACGACGTTGCT; WD repeat domain 43 (Wdr43) sense, GCATACAGTGGCATCAAGAC and antisense, GTGAACCTAAGCGACGAAA; Prominin 1 (Prom1) sense, CTGAAGATTGCCCTCTATGA and antisense, AGTTTCTGGGTCCCTTTGAT; Axin2 sense, TGA CTCTCCTTCCAGATCCCA and antisense, TGCCCACAC TAGGCTGACA; and EPH receptor B3 (Ephb3) sense, GAC CTTGCTGCCCGAAACAT and antisense, CCCACATGA CAATCCCATAGCT; Mus musculus mucin 2 (Muc2) sense, ATGACGTCTGGTGGAATGGT and antisense, TGTTCT GACAGTTGCACGTG; Mus musculus SAM pointed domain containing ets transcription factor (Spdef) sense, TGAACA TCACAGCAGACCCT and antisense, ACTTCCAGATGT CCAGGTGG; Chga chromogranin A (Chga) sense, ACTTCA AGACCTGGCTCTCC and antisense, CCTAGGTCCCTC TGTGGTTG; Mus musculus neurogenin 3 (Nuero3) sense, ACACAACAACCTTTTCCCGG and antisense, CCCGAT CATTGGCCTTCTTG; Mus musculus caudal type homeobox 1 $(C d x l)$ sense, AAGGGTTCCAGAGTGAGGTG and antisense, TAGGGCAGGTGAAAGTGAGG; Mus musculus caudal type homeobox $2(C d x 2)$ sense, CTCTCCTCCTACCCA CGAAC and antisense, TGGGGCAAAAGAGGCTGATA; Mus musculus lysozyme 1 (Lyzl) sense, GCTTCTACTGCA GCCCATTC and antisense, GCTGACTGACAAGGGAGACT; Mus musculus SRY (sex determining region Y)-box 9 (Sox9) sense, CAAGAACAAGCCACACGTCA and antisense, GTG GTCTTTCTTGTGCTGCA; Mus musculus defensin, alpha, 29 (Defa29 or Crs $1 c$ ) sense, AAAGAAGGTTTCCGTGGTGC and antisense, TGAGGCTAAGCACAATGGGA; Mus musculus defensin, alpha, 5 (Defa5) sense, ATTTGTCCTCCTCTCTG CCC and antisense, ACGCGTTCTCTTCTTTTGCA; Axin2 sense, TGACTCTCCTTCCAGATCCCA and antisense, TGC
CCACACTAGGCTGACA; cyclin D1 (Ccnd1) sense, AGT TCATTTCCAACCCACCC and antisense, AGACCAGCC TCTTCCTCCAC; transcriptional regulator Myc-like $(C-m y c)$ sense, CCCTACCCGCTCAACGACAG and antisense, TTG CCTCTTCTCCACAGACACC; Eph receptor B3 (Ephb3) sense, GACCTTGCTGCCCGAAACAT and antisense, CCC ACATGACAATCCCATAGCT; Eph receptor B2 (Ephb2) sense, GGCTTTACCTCTTTCGACG and antisense, CAA TCCCCTTTTCCTTCC; wingless-type MMTV integration site family, member 3A (Wnt3a) sense, GCACCACCGTCA GCAACAGC and antisense, TCCCTGGCATCGGCAAA CTC; Notchl sense, AATGGAGGGAGGTGCGAAGT and antisense, CAGAGGTGTCAGGCAGAGGG; hes family bHLH transcription factor $1($ Hesl) sense, GGAGAAGAG GCGAAGGGCAAGA and antisense, CGTGGACAGGAA GCGGGTCA; jagged 1 (Jagl) sense, AATGGTTATCGC TGTATCTGTCC and antisense, AGTTCTTGCCCTCAT AGTCCTC; delta like canonical Notch ligand 1 (Dll-1) sense, CCGATGACCTCGCAACAGAA and antisense, CCAGGG TCGCACATCTTCTC. $\beta$-actin served as the control gene, all reactions were performed in triplicate. The relative expression was calculated using the $2^{-\Delta \Delta \mathrm{Cq}}$ method (27).

Histological analysis. The intestines were dissected and flushed gently with cold PBS. They were then immediately fixed by $4 \%$ PFA in PBS or snap-frozen on dry ice. Frozen samples were stored at $-80^{\circ} \mathrm{C}$ until cut into frozen slices using a cryostat microtome. Fixed intestines were dehydrated by gradient alcohols, embedded in paraffin, and cut into $4-\mu \mathrm{m}$-thick sections which were then subjected to H\&E staining or immunohistochemistry (IHC).

Organoid histological staining was carried out with the sections or whole-mount sections. For the sections, organoids were collected after Matrigel was melted by Cell Recovery Solution (BD Biosciences). The organoids were then dehydrated and embedded in paraffin. The sections were deparaffinized in xylene and rehydrated in gradient alcohols. Endogenous peroxidase activity was quenched with $3 \% \mathrm{H}_{2} \mathrm{O}_{2}$ in methanol for $20 \mathrm{~min}$ and washed in PBS. Antigen retrieval was performed by boiling the slides in $10 \mathrm{mM}$ sodium citrate buffer, $\mathrm{pH} 6.0$ or $10 \mathrm{mM}$ Tris-base, $1 \mathrm{mM}$ EDTA solution, $\mathrm{pH}$ 9.0. The sections were blocked with $1 \%$ BSA and incubated with the primary antibodies as listed below overnight at $4^{\circ} \mathrm{C}$. For IHC staining, following incubation with secondary antibody (HRP labeled polymer, GK500710; Shanghai Genetech Co., Shanghai, China) for $30 \mathrm{~min}$, the sections were developed with DAB and counterstained with hematoxylin, then dehydrated and mounted in neutral resins. For BrdU staining, before fixture, the organoids were treated with $3 \mu \mathrm{g} / \mathrm{ml}$ BrdU for $2 \mathrm{~h}$. A similar procedure was performed with the addition of a 30-min treatment with $2 \mathrm{~N} \mathrm{HCl}$ after antigen retrieval. For immunofluorescence (IF), the sections, following primary antibody as listed below incubation overnight at $4^{\circ} \mathrm{C}$ were washed and incubated with secondary Alexa Fluor 488 (1:500 dilution; cat. no. ab150077; Abcam, Cambridge, MA, USA) or 647 antibodies (1:500 dilution; cat. no. ab150115; Abcam) for $2 \mathrm{~h}$ at room temperature with DAPI (1:10,000 dilution; cat. no. ab104139; Abcam) counterstaining for $5 \mathrm{~min}$ at room temperature (Thermo Fisher Scientific) and subjected 
to immunofluorescence microscopy (BX53; Olympus Corporation, Tokyo, Japan).

For the whole-mount sections, the organoids were fixed with $4 \%$ PFA in a plate without melting the Matrigel, then permeabilized with $0.2 \%$ Triton in PBS and incubated overnight with primary antibodies as listed below. Fluorescence was detected as mentioned above.

The primary antibodies were as follows: Cleaved caspase-3 (1:200; cat. no. 9661; Cell Signaling Technology, Danvers, MA, USA), Ki67 (1:2,000; cat. no. ab873; Abcam), Lysozyme (Paneth cell marker; 1:2,000; cat. no. ab108508; Abcam), Chromogranin A (endocrine cell marker; 1:2,000; cat. no. 20085; ImmunoStar, Hudson, WI, USA), Muc2 (goblet cell marker; 1:100; cat. no. sc-59859; Santa Cruz Biotechnology, Inc.,), phosphor-Stat3 at Tyr705 (1:200; cat. no. 4113; Cell Signaling Technology), BrdU (1:500; cat. no. B8434; Sigma-Aldrich; Merck KGaA) and IL-22RA1 (1:400; cat. no. ab211675; Abcam).

Flow cytometry. Lgr5-EGFP-IRES-creERT2 mice (Stock no. 008875) were obtained from The Jackson Laboratory (Bar Harbor, ME, USA) and a total of 5 male, Lgr5-EGFP-IRES-creERT2 mice (8 weeks old, weighing approximately $20 \mathrm{~g}$ ) were kept under SPF experiment animal conditions (temperature, $23 \pm 2^{\circ} \mathrm{C}$; humidity, $65 \pm 5 \%$ ) in a 12 -h light/dark cycle and fed a standard laboratory diet and water in East China Normal University Center for Animal Research. Endogenous GFP (green) driven by Lgr5 promoter indicates crypt base columnar stem cells in the small intestine. Crypts from the Lgr5-EGFP-IRES-CreERT2 mice were isolated as described above after the mice were sacrificed and organoid culture was performed. Following treatment with $100 \mathrm{ng} / \mathrm{ml}$ recombinant mouse IL-22 (R\&D Systems, Inc., Minneapolis, MN, USA), organoids were collected and dissociated with TypLE and 2,000 U/ml DNase for $15 \mathrm{~min}$ at $37^{\circ} \mathrm{C}$. The dead cells were then excluded by scatter characteristics and propidium iodide. $\operatorname{Lr}^{+} 5^{+}$ISCs were identified by their endogenous GFP expression.

Western blot analysis. Organoids were collected after Matrigel melting. The cells were then lysed with $0.5 \%$ NP-40 lysis buffer [50 mM Tris-base (pH 7.4), $150 \mathrm{mM} \mathrm{NaCl,1 \%}$ Triton X-100, $1 \%$ sodium deoxycholate, $0.1 \%$ SDS and Complete Mini Protease Inhibitor mixture (Roche Diagnostics)] for western blot analysis. The protein concentration was determined using a BCA Protein Assay kit (cat. no. p0011; Beyotime, Shanghai, China). The proteins (30 $\mu \mathrm{g}$ each sample) were resolved on $12 \%$ SDS-PAGE gels, transferred onto PVDF membranes (EMD Millipore, Billerica, MA, USA). Following blocking with PBS containing 3\% skim milk, the membranes were incubated overnight at $4^{\circ} \mathrm{C}$ with primary antibodies as follows: Anti-cleavedcaspase-3(1:1,000; cat.no.9661), anti-Bax (1:1,000; cat. no. 2772), anti-Bcl2 (1:1,000; cat. no. 3498), anti-Bcl-xL (1:1,000; cat. no. 2762), anti-Stat3 (1:1,000; cat. no. 9139), anti-phospho-Stat3 (Tyr705; 1:1,000; cat. no. 9145) (all from Cell Signaling Technology) and anti- $\beta$-actin $(1: 1,000$; cat. no. A1978; Sigma-Aldrich; Merck KGaA). Following incubation with peroxidase AffiniPure secondary antibodies (goat anti-mouse IgG, cat. no. 115-035-003; goat anti-rabbit IgG, cat. no. 111-035-003; Jackson ImmunoResearch Laboratories,
Inc., West Grove, PA, USA) for $1 \mathrm{~h}$ at room temperature, the blots were then analyzed using the ECL detection system or scanned with an Odyssey Infrared Imager (LI-COR Biosciences, Lincoln, NE, USA).

Enzyme-linked immunosorbent assay (ELISA). The colons from mice with DSS-induced colitis were obtained and completely homogenized in PBS containing proteinase inhibitors. Following centrifugation at $825 \mathrm{x} \mathrm{g} / \mathrm{min}$ for $20 \mathrm{~min}$, the supernatant was collected. The level of secreted IL-22 from IECs was measured using a mouse IL-22 ELISA kit (Abcam) following the manufacturer's instructions. The experiment was repeated 3 times.

Statistical analysis. Data were statistically analyzed by one-way ANOVA or the Student's t-test. A value of $\mathrm{P}<0.05$ considered to indicate a statistically significant difference. Results are presented as the means \pm standard error of the means (SEM).

\section{Results}

IL-22 is dynamically expressed during intestinal inflammation. We first detected the gene transcription of $I L-22 R A I$ and $I L-10 R B$, heterodimeric receptors of IL-22, in both immune cells and IECs by RT-qPCR. While $I L-22 R A I$ was specifically expressed in epithelial cells, $I L-10 R B$ expression was found in both immune and IECs (Fig. 1A). The results of immunohistochemistry revealed that $I L-22 R A I$ was expressed in the epithelium of the colon and intestine (Fig. 1B). These data suggest IL-22 signaling functions in the intestinal epithelium.

We then examined IL-22 expression in the colon in a mouse model of DSS-induced colitis. Histological analysis revealed that damage to the intestinal epithelium gradually increased, being most severe on day 6 (1 day after DSS administration), and were recovered from day 8 to day 12 (3rd day to the 7th day after DSS administration) (Fig. 1C). Notably, IL-22 expression was consistently altered with the development of colitis. It reached maximum levels on day 6 following DSS administration and decreased during the regeneration of the intestinal epithelium (Fig. 1D and E). In another mouse model of irradiation, we observed similar results (Fig. 1F and G). Taken together, our results reveal that IL-22 expression is associated with the state of intestinal damage.

IL-22 regulates the formation of intestinal organoids. As it is well known that IL-22 promotes cell proliferation during tissue repair, we wished to explore the direct function of IL-22 in IECs. In an extra in vitro organoid culture system, we found that IL-22 treatment led the organoids acquiring a rounded shape and they began to degenerate after 3 days (Fig. 2A). On day 4 , the buds of the organoids were significantly decreased and almost all organoids were disrupted in the IL-22-treated group (Fig. 2B-D).

Subsequently, to determine the mechanisms through which IL-22 regulates organoid formation, we assessed the proliferation and apoptosis of IECs following IL-22 treatment. IHC staining for BrdU and Ki67 revealed that the majority of the cells were in a proliferative state (Fig. 2E). By contrast, we failed to detect a marked difference in cell apoptosis between the vehicle (the organoid cultured without IL-22) and the 
A

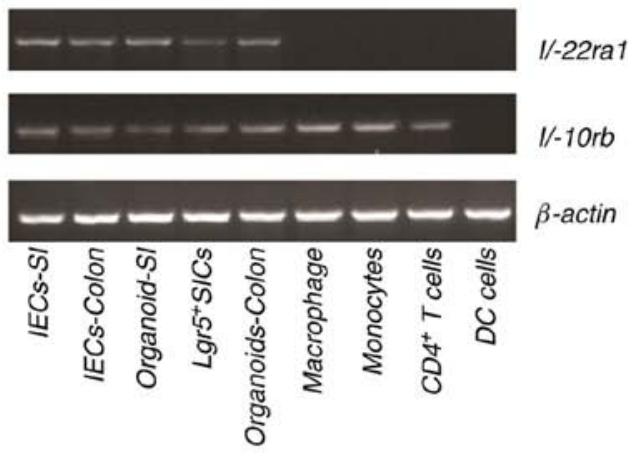

C
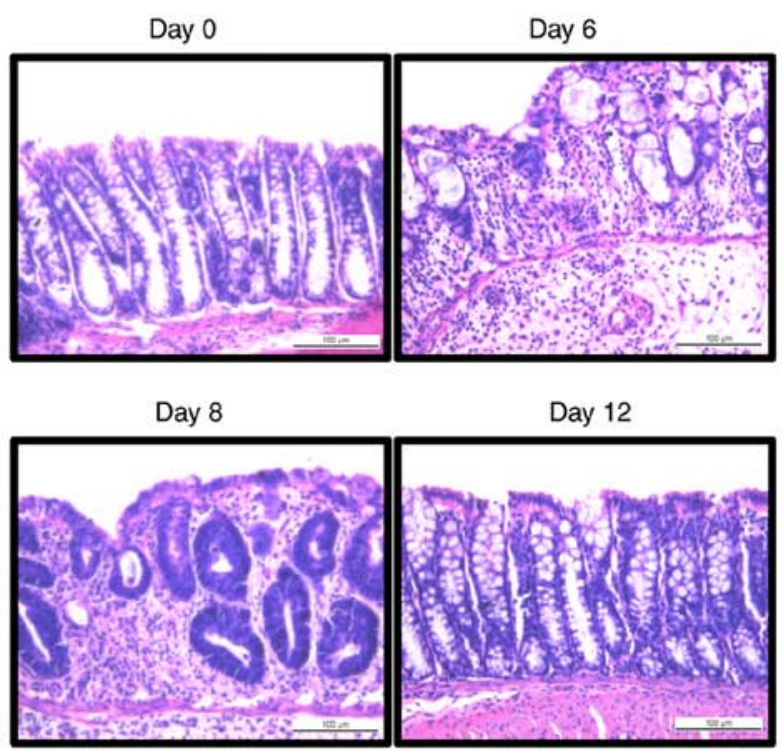

$\mathrm{F}$

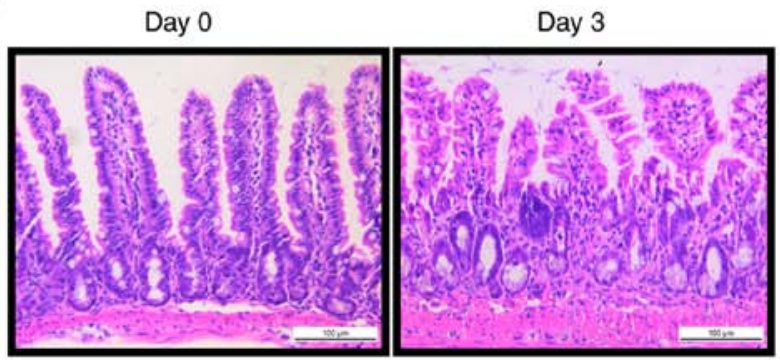

B

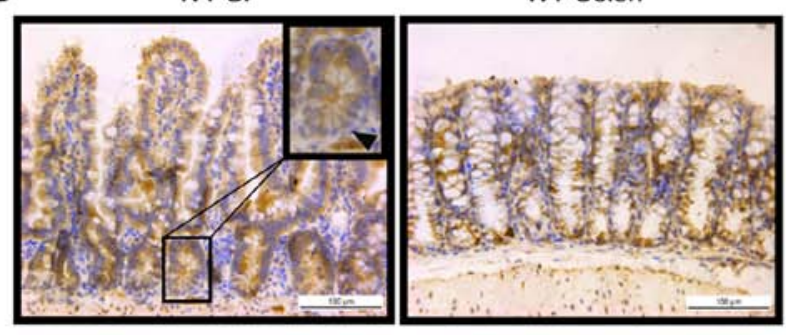

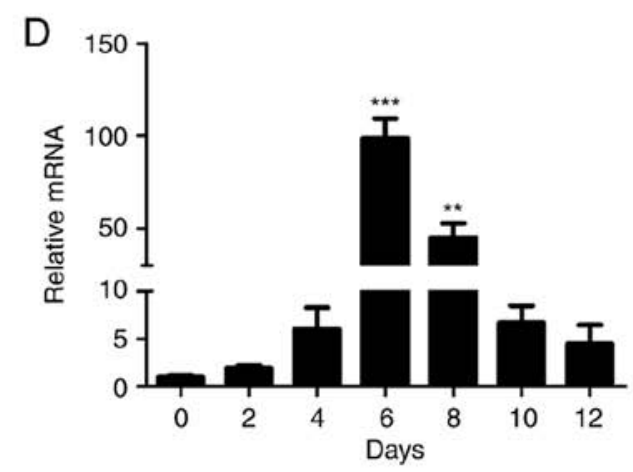
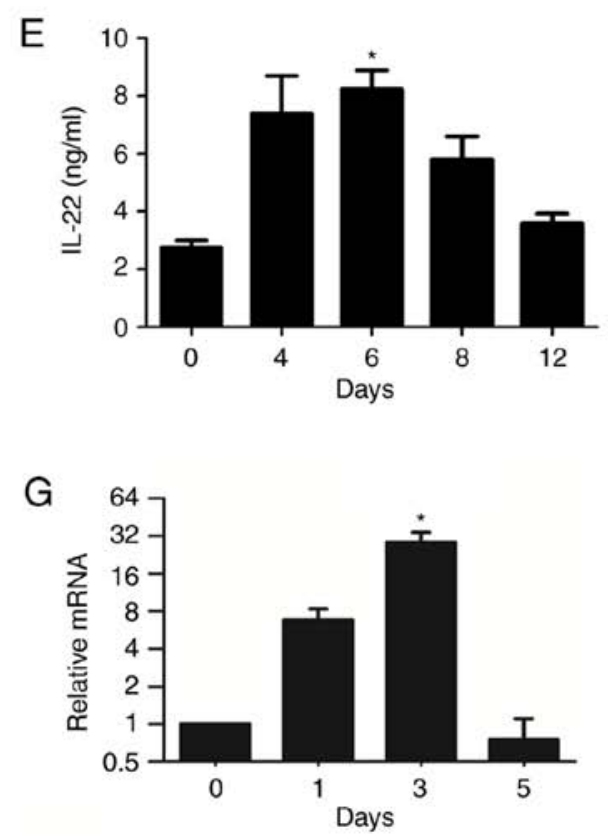

Figure 1. Interleukin (IL)-22 is dynamically expressed during intestinal inflammation. (A) The expression of IL-22RA1 and IL-10RB in different cell types was detected by RT-qPCR. IECs-SI indicates the intestinal epithelium cells from small intestine, immune cells containing macrophages, monocytes, CD4 ${ }^{+} \mathrm{T}$ cells and dendritic cells (DCs). (B) Immunohistochemical staining of paraffin-emdedded sections of the small intestine and colon from wild-type (WT) mice by IL-22RA1 antibody $(\mathrm{n} \geq 3)$. Scale bar, $100 \mu \mathrm{m}$. The inset is the magnification of one representative crypt and the black arrowhead points to the intestinal stem cell (ISC). (C) H\&E staining of colon from WT mice at different time points during dextran sodium sulfate (DSS)-induced inflammatory bowel disease (IBD). Scale bar, $100 \mu \mathrm{m}$. (D) The mRNA expression of IL-22 in colon during DSS-induced IBD in the animal model was determined by RT-qPCR. (E) The secreted IL-22 in the colon during DSS-induced IBD in the animal model was measured by ELISA. (F) H\&E staining of the intestine from WT mice on days 0 and 3 after X-ray radiation. Scale bar, $100 \mu \mathrm{m}$. (G) The mRNA expression of IL-22 in the intestine was examined by RT-qPCR in the X-ray model. Data are the means \pm SEM; ${ }^{*} \mathrm{P}<0.05,{ }^{* *} \mathrm{P}<0.01$, and ${ }^{* * *} \mathrm{P}<0.001$ vs. day 0 ; analyzed by one-way ANOVA $(\mathrm{n}=5)$.

IL-22-treated samples, as determined by measuring the levels of apoptosis-related markers (Fig. 2E and F).

We then wished determine whether IL-22 affects the differentiation of IECs. The results of IF staining revealed that the numbers of different differentiated cell types, including Paneth cells, goblet cells and enteroendocrine cells were significantly decreased following IL-22 treatment (Fig. 2G and H). In addition, the expression of specific markers of differentiated cells was suppressed by IL-22, as shown by RT-qPCR (Fig. 2I). Collectively, these results indicated that IL-22 regulates organoid formation through activation of cell proliferation and inhibition of IECs differentiation. 
$\mathrm{B}$
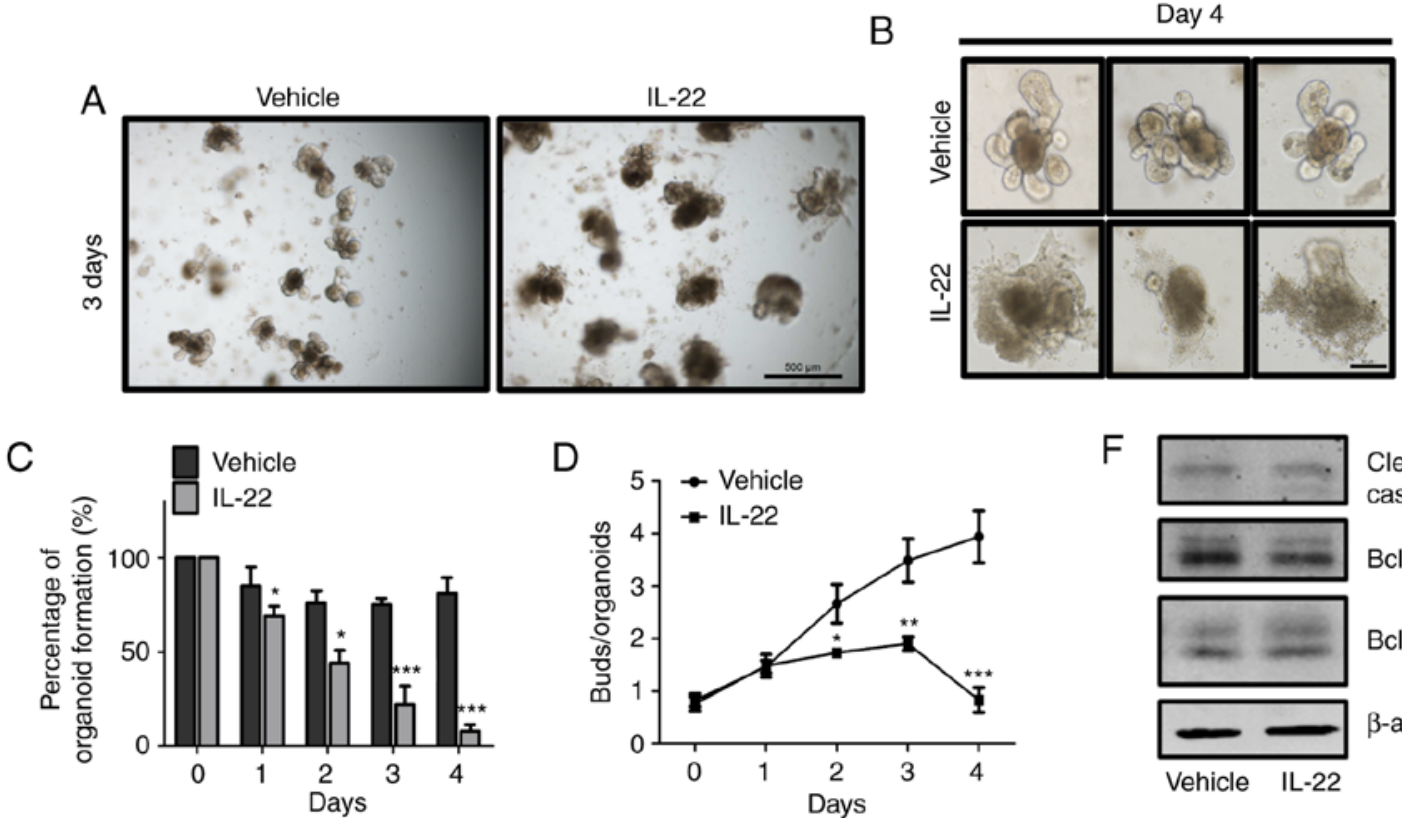

$\mathrm{F}$

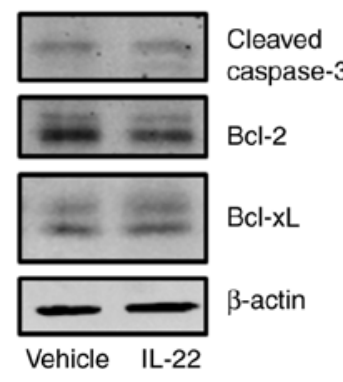

$E$

Vehicle
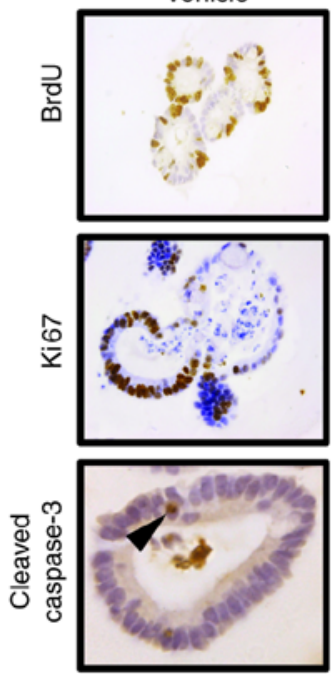

IL-22
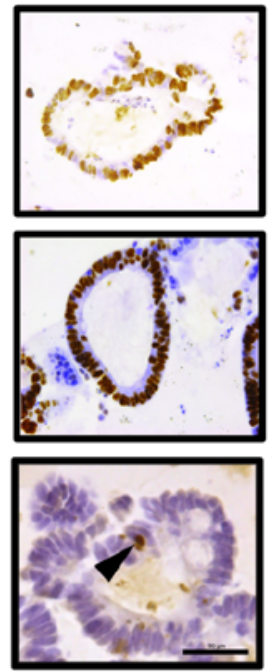

G
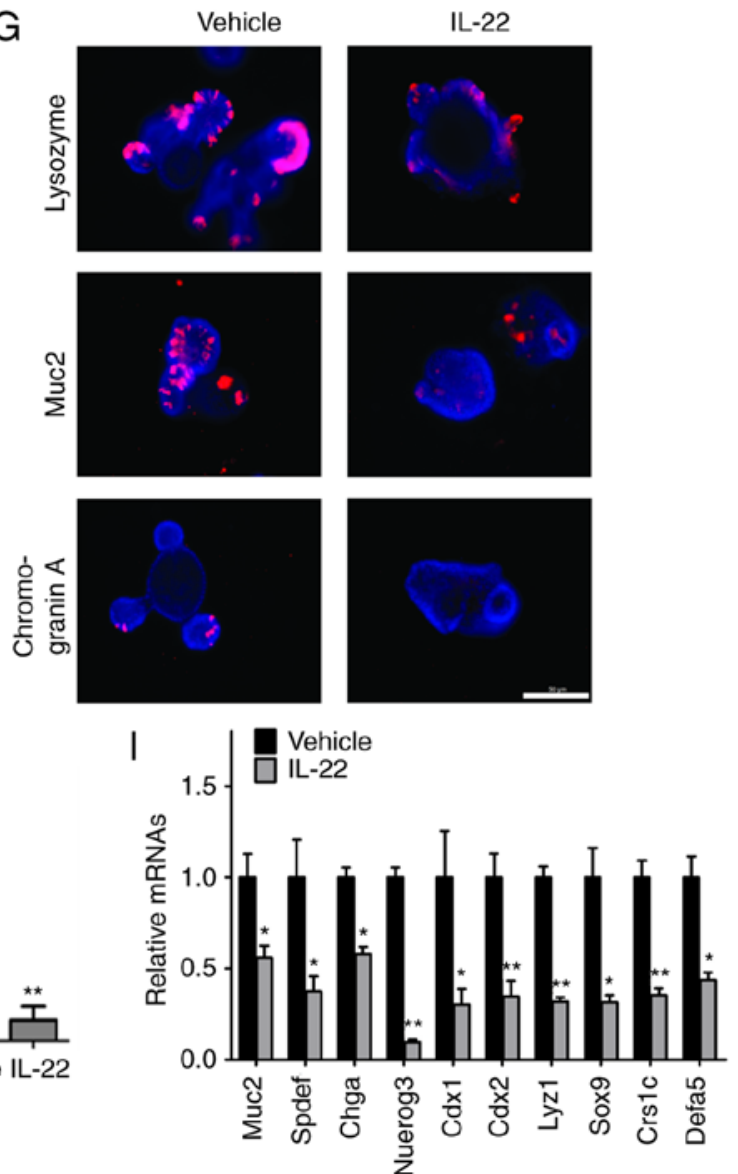

$\mathrm{H}$
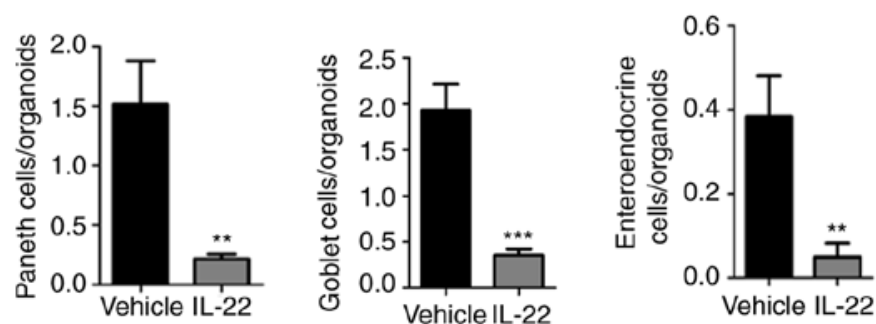

Figure 2. Interleukin (IL)-22 regulates growth of intestinal organoids. (A) Organoids were cultured for 2 days followed by treatment with the vehicle (the organoid cultured without IL-22, left panel) or IL-22 (100 ng/ml treatment group, right panel); representative images are shown on day 3 after treatment. Scale bar, $500 \mu \mathrm{m}$. (B) Organoids were cultured for 2 days followed by treatment with the vehicle (upper panels) or IL-22 (100 ng/ml, bottom panels); representative 3 images are shown on day 4 after treatment. Scale bar, $50 \mu \mathrm{m}$. (C and D) Organoids were cultured for 2 days followed by treatment with the vehicle or IL-22 (100 ng/ml). The percentage of (C) organoid formation and (D) the number of buds are shown at different time points after treatment. Data are the means \pm SEM; ${ }^{*} \mathrm{P}<0.05,{ }^{* *} \mathrm{P}<0.01$, and ${ }^{* * *} \mathrm{P}<0.001$ vs. the vehicle at the indicated time points; analyzed by t-test. (E) Organoids were cultured for 2 days followed by treatment with the vehicle or IL-22 (100 ng/ml). The expression of BrdU, Ki67 and cleaved caspase-3 was detected by immunohistochemical staining. Arrowheads indicate apoptotic cells. Scale bar, $50 \mu \mathrm{m}$. (F) Immunoblotting of cleaved caspase-3, Bcl 2 and Bcl-xL in the organoids treated with or without IL-22 for 2 days (100 ng/ml). (G) The expression of Lysozyme (Paneth cell marker), Muc2 (goblet cell marker) and chromogranin A (endocrine cell marker) was determined by immunofluorescence. Scale bar, $50 \mu \mathrm{m} .(\mathrm{H})$ Quantitative analysis of the data in $(\mathrm{G})$ are presented. Data are the means $\pm \mathrm{SEM} ;{ }^{* *} \mathrm{P}<0.01$ and ${ }^{* * * *} \mathrm{P}<0.001$ vs. the vehicle; analyzed by t-test. (I) Organoids were cultured for 2 days followed by treatment with the vehicle or IL-22 (100 ng/ml). The expression of Muc2, Spdef (goblet cell marker), Chga, Nuerog3 (enteroendocrine cell marker), Cdx1, Cdx2 (columnar absorptive cell marker), Lyz1, Sox9, Crs1c and Defa5 (Paneth cell marker) was detected by RT-qPCR. Data are the means $\pm \mathrm{SEM} ;{ }^{*} \mathrm{P}<0.05,{ }^{* *} \mathrm{P}<0.01$, and vs. vehicle; analyzed by t-test. 
A

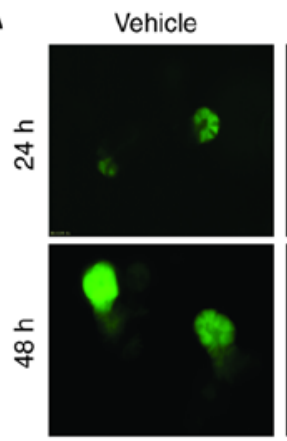

IL-22
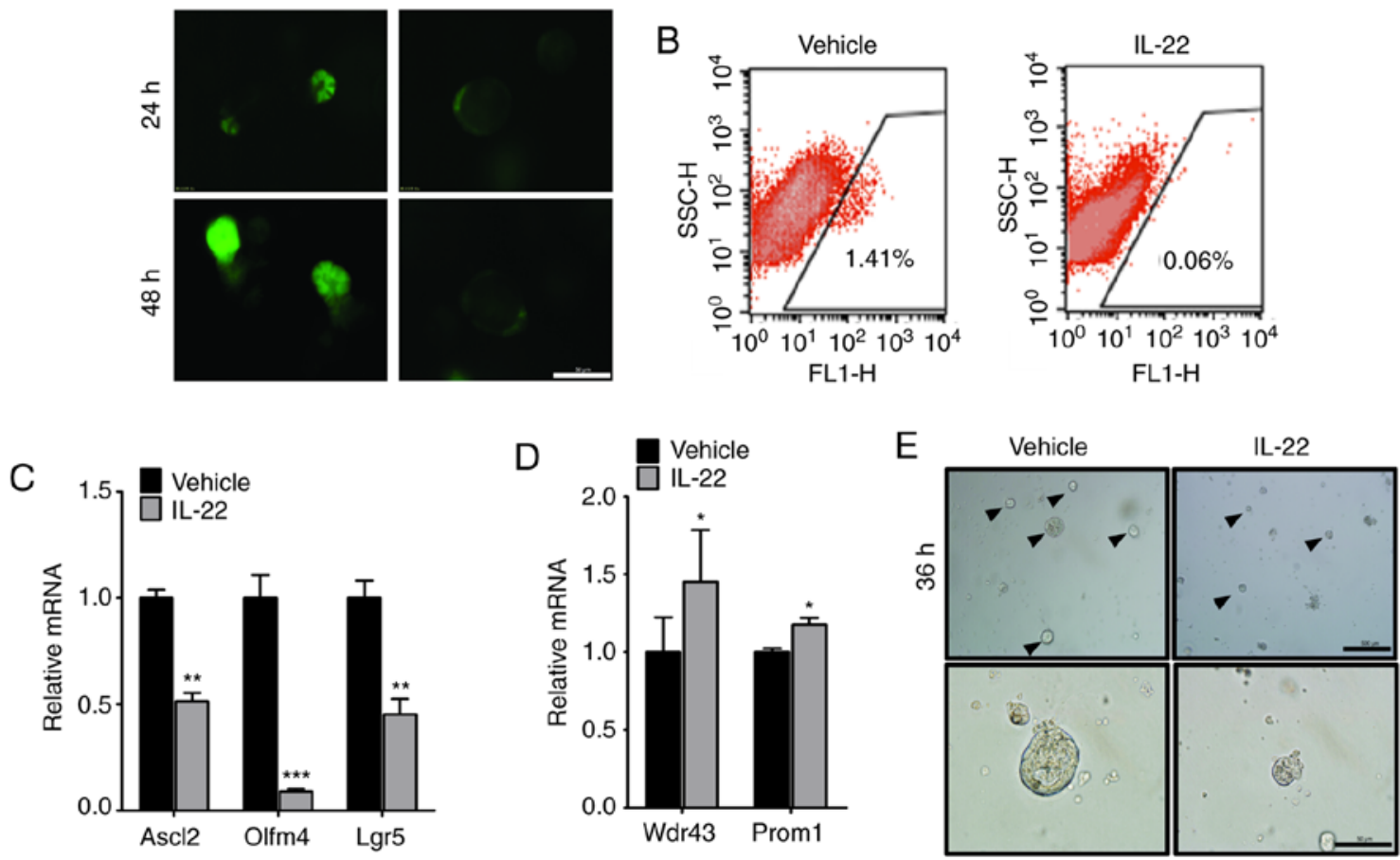

Figure 3. Interleukin (IL)-22 counteracts the self-renewal of intestinal stem cells (ISCs). (A) Organoids from Lgr5-EGFP-IRES-creERT2 mice were treated with or without IL-22 (100 ng/ml); representative images of Lgr5-GFP-positive cells are shown. Scale bar, $50 \mu \mathrm{m}$. (B) Organoids from $L g r 5$-EGFP-IRES-creERT2 mice were treated with or without IL-22 (100 ng/ml) for $40 \mathrm{~h}$, and they were then disassociated to single cells and analyzed by FACS. The percentage of Lgr5-GFP positive cells is shown. (C and D) RT-qPCR analysis of the expression of (C) ISC markers or (D) transit-amplifying (TA) cell markers in the organoids treated with or without IL-22 (100 ng/ml). Data are the means \pm SEM; ${ }^{*} \mathrm{P}<0.05,{ }^{* *} \mathrm{P}<0.01$ and ${ }^{* * * *} \mathrm{P}<0.001$ vs. the vehicle, analyzed by t-test. (E) Single cells were dissociated from the organoids following culture for 4-6 days. The cells were then treated with or without IL-22 (100 ng/ml) for 36 h. Cysts formed from single ISCs are indicated (arrowheads). Scale bar, $500 \mu \mathrm{m}$. The magnified images are shown at the bottom panels. Scale bar, $50 \mu \mathrm{m}$.

IL-22 counteracts the self-renewal ability of ISCs. Paneth cells provide EGF, Notch and Wnt ligands to maintain ISC self-renewal ability, which is essential for organoid formation. Since IL-22 was found to inhibit the differentiation of Paneth cells, we wished to determine whether it also affects ISCs self-renewal. By isolating the organoids from Lgr5-EGFP-IRES-creERT2 mice, we found that the number of ISCs, positive for Lgr5-EGFP, was markedly decreased by IL-22 (Fig. 3A and B). Consistently, the results of RT-qPCR revealed that the expression of stem cell markers, including Ascl2, Olfm4 and Lgr5 was significantly lower in the group treated with IL-22 (Fig. 3C). Moreover, the expression of Wdr43 and Prom1, the transit-amplifying (TA) cells markers, was slightly upregulated by IL-22. This suggested that IL-22 promotes the differentiation into TA cells from $\mathrm{Lgr} 5^{+} \mathrm{ISC}$ (Fig. 3D).

To further validate the effects of IL-22 on the maintenance of ISC self-renewal, we disassociated the organoids into single cells and assessed the growth ability. We observed that the single cells could individually grow to a cyst-like structure and finally formed an organoid structure (Fig. 3E, arrowheads). On the contrary, these cells could not survive following culture for 3-4 days with the addition of IL-22 (Fig. 3E, bottom panels). Taken together, these data suggest that IL-22 counteracts the self-renewal ability of ISCs.

IL-22 promotes the phosphorylation of Stat3 and suppresses the Wnt and Notch signaling pathways. It has been reported that IL-22 modulates the phosphorylation of Stat3 $(18,28)$. In this regard, we assessed the changes in the levels of phosphorylated Stat 3 following treatment of the organoids with IL-22. In the assay of immunofluorescence, we observed that the addition of IL-22 increased the level of phosphorylated Stat 3 in the nucleus of the organoids (Fig. 4A and C). Consistently, similar results were got by immunoblotting (Fig. 4B). Moreover, in the organoids of Lgr5-EGFP-IRES-creERT2 mice, increased levels of nuclear phosphorylated Stat 3 were observed in the Lgr5-positive ISCs following treatment with IL-22 (Fig. 4C).

We then examined the activity of the Wnt and Notch signaling pathways, which are essential for ISC self-renewal and differentiation. It was found that both the Wnt and Notch signaling pathways were markedly suppressed by IL-22 (Fig. 4D and E). In summary, these results demonstrate that IL-22 activates the Stat3, and inhibits the Wnt and Notch signaling pathways.

IL-22 leads to defects in organoid formation mainly through the Wnt pathway. To understand the importance of signaling pathway changes caused by IL-22, we carried out rescue experiments. We applied WP1066 and Stattic as Stat3 specific inhibitors, and added Wnt3a and Jag1 as respective ligands for the Wnt and Notch pathways.

In the absence of IL-22, these supplements did not affect the formation and survival of organoids (Fig. 5A and B). Notably, only the addition of Wnt3a recovered the defects in the organoids induced by the addition of IL-22 (43\% vs. 
A
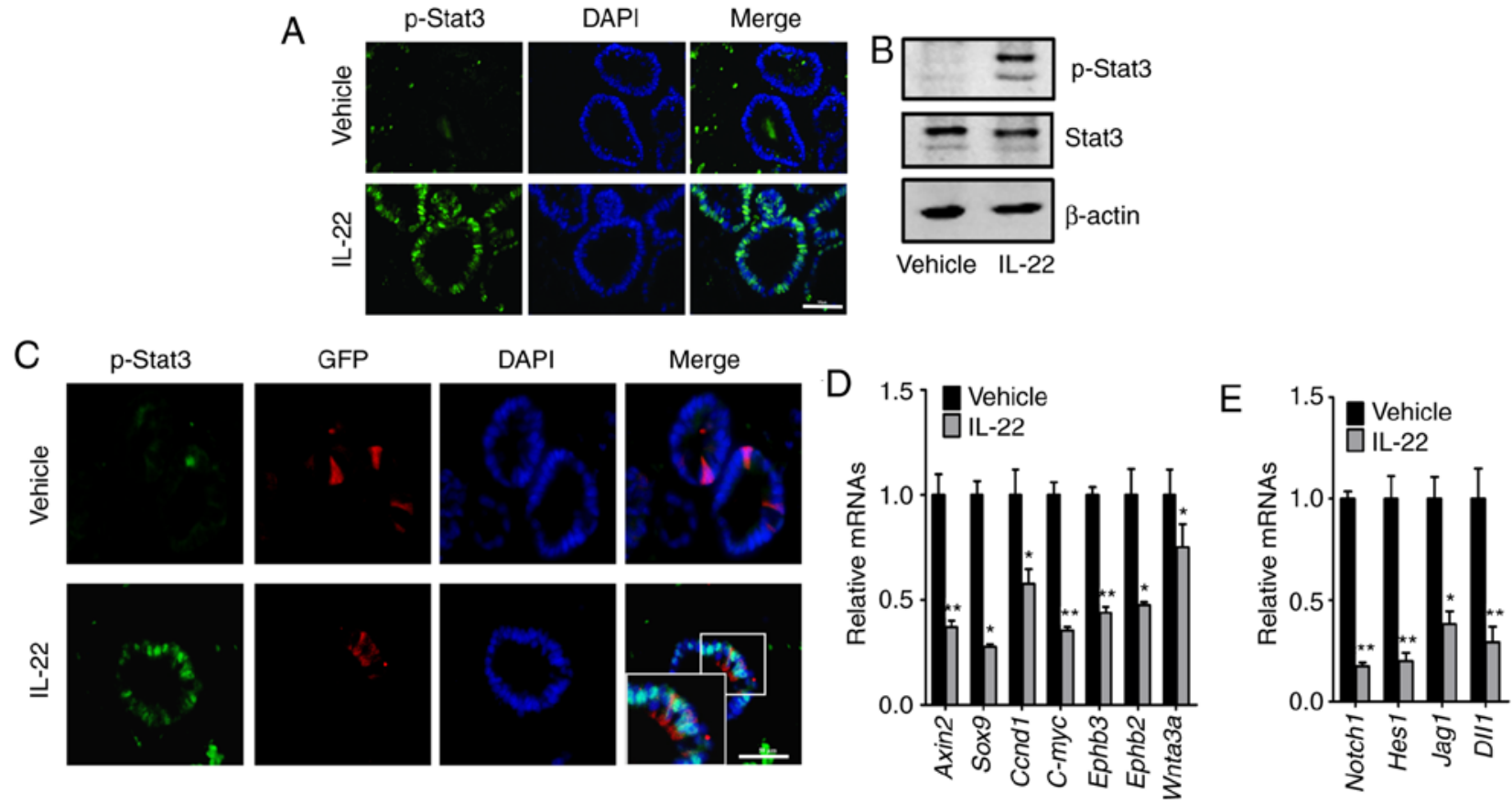

Figure 4. Interleukin (IL)-22 promotes the phosphorylation of Stat3 and suppresses the Wnt and Notch signaling pathways. (A) Organoids were cultured for 2 days followed by treatment with the vehicle or IL-22 $(100 \mathrm{ng} / \mathrm{ml})$. The expression of pospho-Stat 3 at Tyr705 was detected by immunofluorescence. Scale bar, $50 \mu \mathrm{m}$. (B) Western blot analysis of phosphor-Stat3 and total Stat3 in the organoids treated with either the vehicle or IL-22 for $40 \mathrm{~h}(100 \mathrm{ng} / \mathrm{ml})$. (C) Organoids from Lgr5-EGFP-IRES-creERT2 mice were treated with or without IL-22 (100 ng/ml) for $40 \mathrm{~h}$. The expression of phosphor-Stat 3 and GFP was assessed by immunofluorescence. Scale bar, $50 \mu \mathrm{m}$. The inset is the magnification of representative positive staining. (D and E) The expression of target genes of (D) Wnt and (E) Notch signaling pathways was determined by RT-qPCR. Data are the means \pm SEM; ${ }^{*} \mathrm{P}<0.05,{ }^{* *} \mathrm{P}<0.01$ and vs. the vehicle; analyzed by t-test.

7\%; Fig. 5A and B). Furthermore, we found that the number of Paneth cells was retrieved by Wnt3a, but not by Stattic, WP1066 and Jag1 (Fig. 5D). Notably, Stattic treatment significantly restrained IL-22-induced cell hyper-proliferation (Fig. 5C). This observation suggested that IL-22 promotes cell proliferation mainly through Stat3 activation. Consistently, the upregulation of Wnt target genes, including Axin2 and Ephb3, was confirmed by RT-qPCR following the addition of Wnt3a in IL-22-treated organoids (Fig. 5E). Moreover, the levels of ISC markers (Lgr5, Olfm4 and Znrf3) were elevated as well. Taken together, these data suggest that IL-22 caused the deficiency of organoid formation mainly by suppressing the Wnt signaling pathway.

Taken together, in this study, we observed that the IL-22 level initially increased and gradually decreased during inflammation. Elevated IL-22 levels of modulated the Stat3, Wnt and Notch pathways to accelerate the proliferation of TA cells, suppressing cell differentiation and causing the deficiency of ISC self-renewal (Fig. 6).

\section{Discussion}

It has been reported that IL-22 is a dual-natured cytokine depending on the context of inflammation. It has either pro-inflammatory or anti-inflammatory properties $(13,29)$. In the majority of inflammatory bowel disease animal models $(14,18,28,30,31)$, infectious disease (32-34) and graft versus host disease (GVHD) (35), IL-22 plays a protective role against inflammation. By contrast, in a Treg cell transferring animal model and during Toxoplasma gondii-induced ileitis, IL-22 has been shown to play a pro-inflammatory function $(20,36)$. In this respect, a more precise association between IL-22 and epithelial cells needs to be determined. In this study, we used an ex vivo organoid culture system to investigate the role of IL-22 in the homeostasis of intestinal epithelium during inflammation. The advantage of this system is that it can rule out the effects of other cells surrounding the IECs, such as mesenchyme cells and leukocytes. In this manner, we discovered a previously unknown direct association between IL-22 and the intestinal epithelium in that IL-22 promotes the proliferation but inhibits the differentiation of intestinal organoids. Moreover, it suppresses the self-renewal ability of ISCs and consequently leads to the death of organoids. These data reveal that IL-22 has more complex functions in IECs than what was previously known.

Following IL-22 treatment, we observed that the organoids became rounded without buds whose tips were enriched with ISCs and Paneth cells $(21,22,37)$. In addition, fewer terminal differentiated cells were found in IL-22-treated organoids. It has been known that the downregulation of Wnt signaling suppresses EphB expression and thus impairs the ephrinB-EphB repulsion, which is critical for the crypt-villi axis establishment $(38,39)$. Thus, the rounded structure caused by IL-22 treatment is likely attributed to the accelerated proliferation of IECs and the loss of migration axis, causing the cells to detach from the epithelial structures and to shed into the lumen.

In vivo, IL-22 expression was upregulated within 6-8 days of DSS-induced inflammation and on the 3rd day of X-ray radiation-induced inflammation; during this period, the intestine 
A
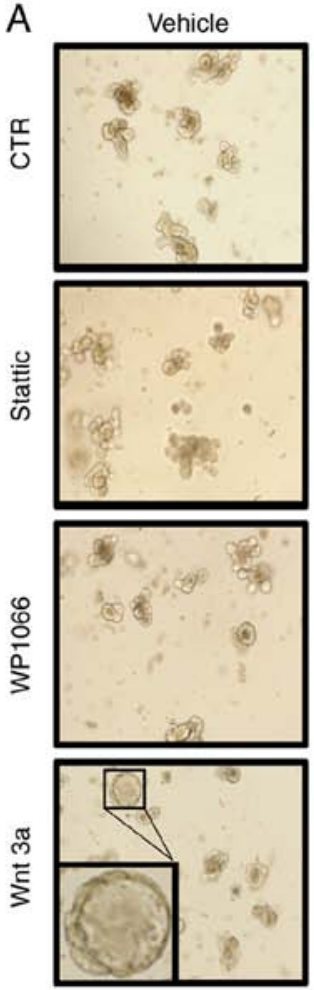

B

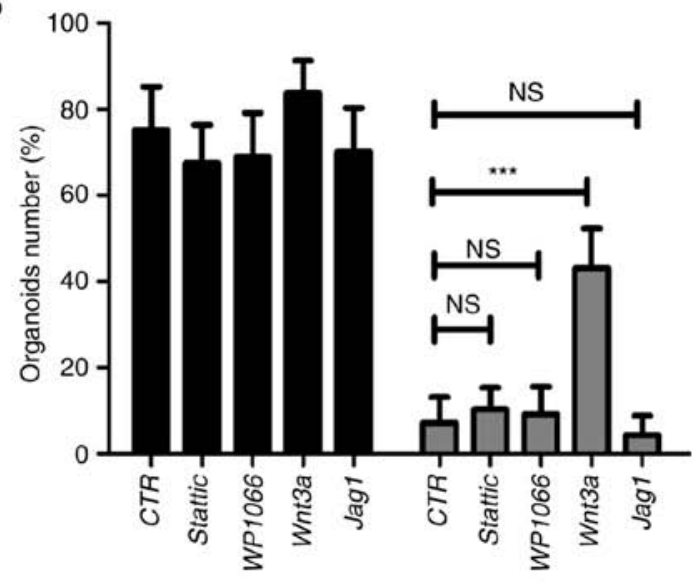

C
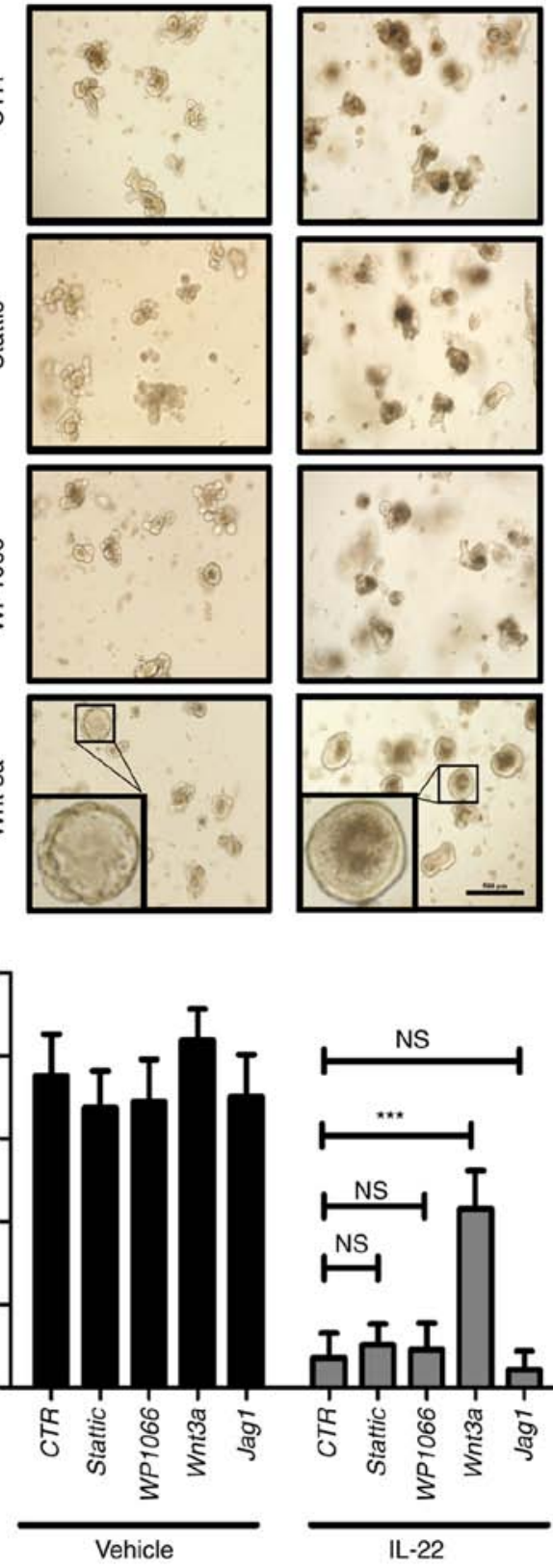

IL-22
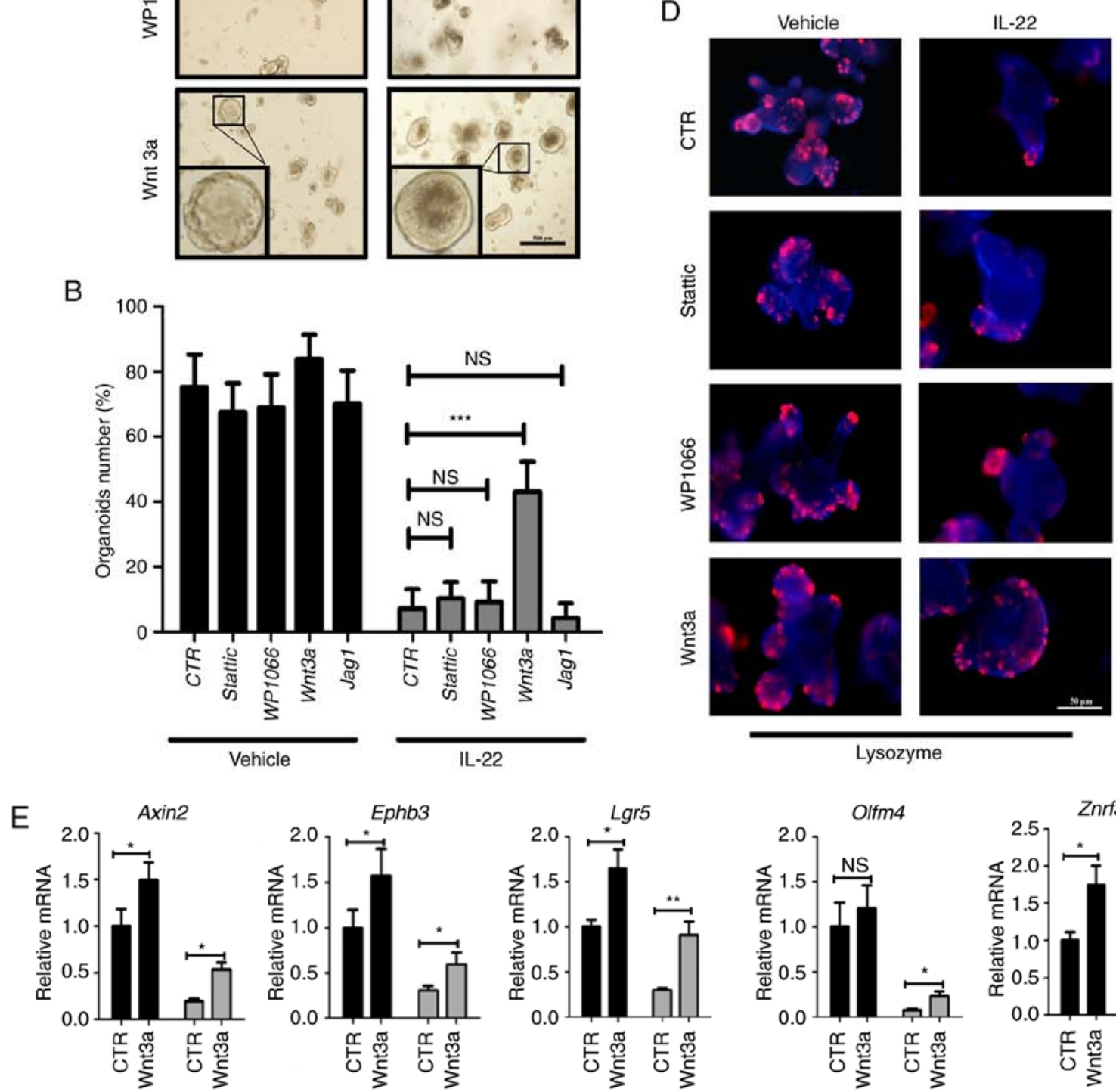

Lysozyme
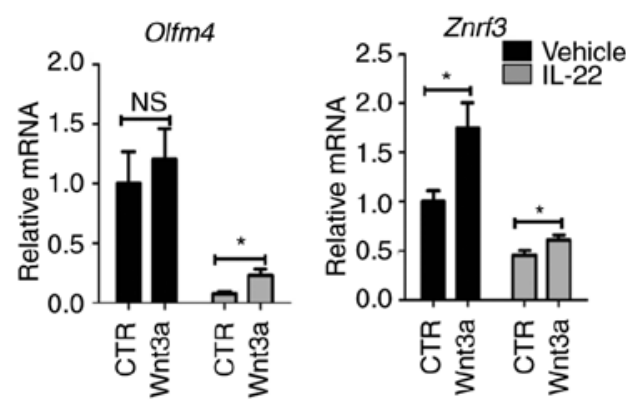

Figure 5. Interleukin (IL)-22 causes defects in organoid formation mainly through the Wnt pathway. (A) Organoids were cultured for 2 days followed by treatment with various combinations of IL-22 $(100 \mathrm{ng} / \mathrm{ml})$, Wnt3a $(200 \mathrm{ng} / \mathrm{ml})$, WP1066 $(5 \mu \mathrm{M})$ and Stattic $(3 \mu \mathrm{M})$. Scale bar, $500 \mu \mathrm{m}$. The inset is the magnification of one representative organoid. (B) The number of organoids after 2 days of treatment with various combinations of IL-22, Wnt3a, WP1066, Stattic and Jag1 was counted. Data are the means $\pm \mathrm{SEM}$; and ${ }^{* * *} \mathrm{P}<0.001$ vs. Control (100 ng/ml IL-22 treatment group); NS, not significant; analyzed by one-way ANOVA. (C) Organoids were cultured for 2 days followed by treatment with various combinations of IL22 and Stattic. The expression of Ki67 was detected by immunohistochemical staining. Scale bar, $50 \mu \mathrm{m}$. The quantitative analysis is presented at the bottom panel. Data are the means $\pm \mathrm{SEM}$; ${ }^{*} \mathrm{P}<0.05,{ }^{* *} \mathrm{P}<0.01$ and vs. the vehicle; analyzed by one-way ANOVA. (D) Organoids were cultured for 2 days followed by treatment with various combinations of IL-22, Wnt3a, WP1066 and Stattic. The expression of Lysozyme (Paneth cell marker) was determined by immunofluorescence. Scale bar, $50 \mu \mathrm{m}$. (E) Organoids were cultured for 2 days followed by treatment with various combinations of IL-22 and Wnt3a. The expression of ISC markers (Lgr5, Olfm4 and Znrf3) and Wnt target genes (Axin2 and Ephb3) was examined by RT-qPCR. Data are the means \pm SEM; ${ }^{*} \mathrm{P}<0.05,{ }^{* *} \mathrm{P}<0.01$ and vs. Control (the organoid cultured without IL-22) or Control $(100 \mathrm{ng} / \mathrm{ml} \mathrm{IL}-22$ treatment group); analyzed by t-test. 


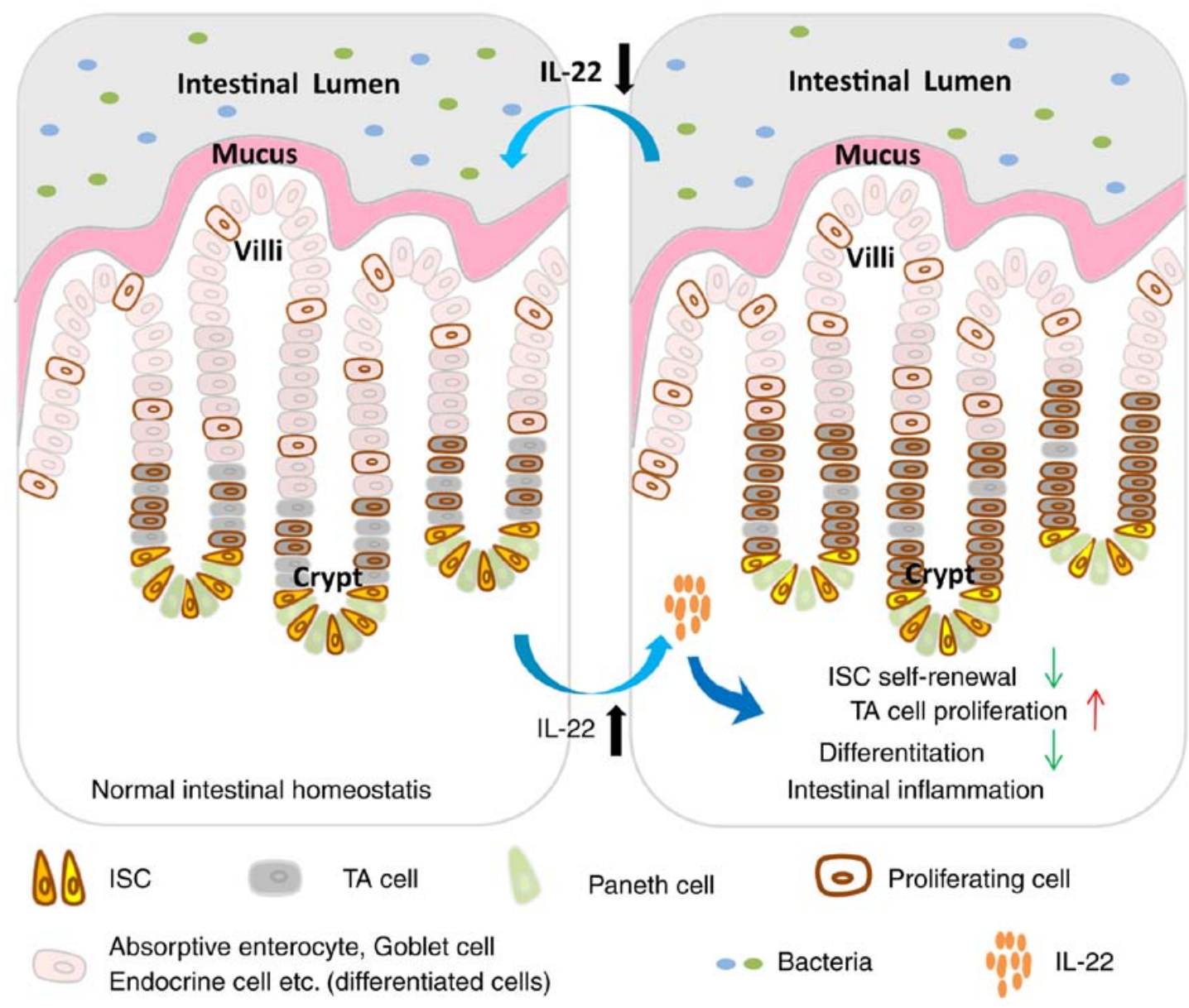

Figure 6. Interleukin (IL)-22 regulates the homeostasis of intestine epithelium during inflammation. During inflammation, elevated IL-22 promotes the proliferation of TA cells, represses cell differentiation and leads to the self-renewal defect of intestinal stem cells. Later, the level of IL-22 gradually reduces and the homeostasis of intestine epithelium is recovered.

incurs the most severe inflammatory response. We postulate that high level of IL-22 promotes anti-microbial peptide expression and alleviates the bacterial burden, which is critical for the initiation of intestinal regeneration $(32,40,41)$. However, following bacterial clearance, the epithelium begins to recover and reconstitute; the limitation of IL-22 is important for IEC differentiation. The decreased IL-22 level is possible due to the reduced number of adaptive immune cells, such as Th17 and Th22, which are the source of IL-22, while responding the inflammatory stresses and bacterial states $(33,42-44)$.

The stem cell niche is indispensable for the homeostasis of the intestinal epithelium. In this study, we observed that IL-22 activates Stat3 signaling to promote the hyper-proliferation of intestinal organoids. Moreover, IL-22 inhibited the Wnt and Notch signaling pathways in IECs. Notably, only Wnt3a rescued the organoid defects caused by IL-22, which suggests that the Wnt pathway is a key factor, downstream of IL-22, to regulate intestinal homeostasis. A recent study indicated that Wnt signaling synergizes with R-spondin to maintain ISC self-renewal (45). However, the mechanisms through which IL-22 influences the Wnt pathway remain unclear. One possibility is that IL-22 directly modulates important players controlling Wnt signaling. Another possibility is that IL-22 suppresses the differentiation of Paneth cells which secret Wnt ligands for ISCs and IECs.
Our results are not consistent with those from a previous study, which demonstrated that IL-22 maintained the self-renewal ability of Lgr5-positive stem cells by using an IL-22 knockout mouse strain (35). IL-22 has been reported to have diverse functions in the intestine. For example, it can promote antibacterial peptide secretion and mucus production (18). We hypothesized that the loss of IL-22 may cause global consequences, such as impairing bacterial clearance, and therefore leads to the destruction of the intestinal barrier and structure. Inconsistently, another study recently demonstrated that IL-22 promotes the proliferation and expansion of ISCs in intestinal organoids (46). Of note, we used a much higher concentration of IL-22 (100 ng/ml vs. 5-10 ng/ml) in this study. This is more coincident with the high level of IL-22 expression during inflammation (47). We reason that a greater amount of IL-22 likely reaches a certain threshold that causes the suppression of Wnt signaling. Additionally, given that IL-22 receptors are also bound to other cytokines (10,48-50), a greater amount of IL-22 may competitively inhibit other signaling, such as IL-20 and IL-24 (48), which affect ISC self-renewal.

Given that IL-22 is well documented to regulate barrier immunity and anti-microbiota, it is considered to play a protective role in IBD (51). Agents to activate the IL-22 pathway are being developed for the treatment of patients with IBD. For 
example, Indigo naturalis has been shown to be beneficial for ulcerative colitis in a clinical trial (52). However, a previous study demonstrated that the continuous stimulation of IL-22 potentially increases the risk of colitis-associated cancer (53). In this study, we found that the dynamic alteration of IL-22 was important for the maintenance of intestinal homeostasis during inflammation (Fig. 6), which sheds light into the role of IL-22 in regulating the homeostasis of the intestinal epithelium during inflammation. Thus, this study suggests that a prolonged administration of agents to activate the IL-22 pathway for IBD treatment may not be beneficial. Our findings further the current understanding of IL-22 and may aid in the clinical therapy of IBD.

In conclusion, in this study, we found that IL-22 treatment promoted cell proliferation, suppressed the differentiation of intestinal organoids and led to self-renewal defects of intestinal stem cells. As regards the underlying mechanisms, IL-22 activated Stat 3 phosphorylation and suppressed the Wnt and Notch signaling pathways. This study reveals that IL-22 regulates the homeostasis of the intestinal epithelium and is critical for the regeneration of the intestine during inflammation. Thus, it deepens our current understanding of the regulation and function of IL-22 and provides the theoretical basis for IBD treatment.

\section{Acknowledgements}

Not applicable.

\section{Funding}

This study was supported by the National Natural Science Foundation of China (grant no. 81772622 to JZ) and the Animal Research Project of Shanghai Science and Technology Commision (grant no. 16140902000 to $\mathrm{XuZ}$ ).

\section{Availability of data and materials}

All data generated or analyzed during this study are included in this published article.

\section{Authors' contributions}

XiZ, JZ, YC, XuZ designed the experiments. XiZ, SL, YWa, HH, LL performed the experiments. SL DC and YWu performed the data analysis. YWu contributed materials/facilities. XiZ, JZ, YC and XuZ wrote the manuscript. All authors have read and approved the final manuscript.

\section{Ethics approval and consent to participate}

All animal experiments conformed to the regulations drafted by the Association for Assessment and Accreditation of Laboratory Animal Care in Shanghai and were approved by the East China Normal University Center for Animal Research.

\section{Patient consent for publication}

Not applicable.

\section{Competing interests}

The authors declare that they have no competing interests.

\section{References}

1. Sturm A and Dignass AU: Epithelial restitution and wound healing in inflammatory bowel disease. World J Gastroenterol 14: 348-353, 2008.

2. Artis D: Epithelial-cell recognition of commensal bacteria and maintenance of immune homeostasis in the gut. Nat Rev Immunol 8: 411-420, 2008.

3. Hooper LV and Macpherson AJ: Immune adaptations that maintain homeostasis with the intestinal microbiota. Nat Rev Immunol 10: 159-169, 2010.

4. Kreymborg K, Etzensperger R, Dumoutier L, Haak S, Rebollo A, Buch T, Heppner FL, Renauld JC and Becher B: IL-22 is expressed by Th17 cells in an IL-23-dependent fashion, but not required for the development of autoimmune encephalomyelitis. J Immunol 179: 8098-8104, 2007.

5. Satoh-Takayama N, Vosshenrich CA, Lesjean-Pottier S, Sawa S, Lochner M, Rattis F, Mention JJ, Thiam K, Cerf-Bensussan N, Mandelboim O, et al: Microbial flora drives interleukin 22 production in intestinal $\mathrm{NKp} 46^{+}$cells that provide innate mucosal immune defense. Immunity 29: 958-970, 2008.

6. Cella M, Fuchs A, Vermi W, Facchetti F, Otero K, Lennerz JK, Doherty JM, Mills JC and Colonna M: A human natural killer cell subset provides an innate source of IL-22 for mucosal immunity. Nature 457: 722-725, 2009.

7. Cupedo T, Crellin NK, Papazian N, Rombouts EJ, Weijer K, Grogan JL, Fibbe WE, Cornelissen JJ and Spits H: Human fetal lymphoid tissue-inducer cells are interleukin 17-producing precursors to $\mathrm{RORC}^{+} \mathrm{CD} 127^{+}$natural killer-like cells. Nat Immunol 10: 66-74, 2009.

8. Luci C, Reynders A, Ivanov II, Cognet C, Chiche L, Chasson L, Hardwigsen J, Anguiano E, Banchereau J, Chaussabel D, et al: Influence of the transcription factor RORgammat on the development of $\mathrm{NKp} 46^{+}$cell populations in gut and skin. Nat Immunol 10: 75-82, 2009.

9. Sanos SL, Bui VL, Mortha A, Oberle K, Heners C, Johner C and Diefenbach A: RORgammat and commensal microflora are required for the differentiation of mucosal interleukin 22-producing NKp46 ${ }^{+}$cells. Nat Immunol 10: 83-91, 2009.

10. Ouyang W, Rutz S, Crellin NK, Valdez PA and Hymowitz SG: Regulation and functions of the IL-10 family of cytokines in inflammation and disease. Annu Rev Immunol 29: 71-109, 2011.

11. Sawa S, Lochner M, Satoh-Takayama N, Dulauroy S, Bérard M, Kleinschek M, Cua D, Di Santo JP and Eberl G: ROR $\gamma \mathrm{t}^{+}$innate lymphoid cells regulate intestinal homeostasis by integrating negative signals from the symbiotic microbiota. Nat Immunol 12: 320-326, 2011.

12. Spits $\mathrm{H}$ and Di Santo JP. The expanding family of innate lymphoid cells: Regulators and effectors of immunity and tissue remodeling. Nat Immunol 12: 21-27, 2011.

13. Zenewicz LA and Flavell RA: Recent advances in IL-22 biology. Int Immunol 23: 159-163, 2011.

14. Zindl CL, Lai JF, Lee YK, Maynard CL, Harbour SN, Ouyang W, Chaplin DD and Weaver CT: IL-22-producing neutrophils contribute to antimicrobial defense and restitution of colonic epithelial integrity during colitis. Proc Natl Acad Sci USA 110: 12768-12773, 2013.

15. Xie MH, Aggarwal S, Ho WH, Foster J, Zhang Z, Stinson J, Wood WI, Goddard AD and Gurney AL: Interleukin (IL)-22, a novel human cytokine that signals through the interferon receptor-related proteins CRF2-4 and IL-22R. J Biol Chem 275: 31335-31339, 2000.

16. Kotenko SV, Izotova LS, Mirochnitchenko OV, Esterova E, Dickensheets H, Donnelly RP and Pestka S: Identification of the functional interleukin-22 (IL-22) receptor complex: The IL-10R 2 chain (IL-10Rbeta) is a common chain of both the IL-10 and IL-22 (IL-10-related T cell-derived inducible factor, IL-TIF) receptor complexes. J Biol Chem 276: 2725-2732, 2001.

17. Pestka S, Krause CD, Sarkar D, Walter MR, Shi Y and Fisher PB: Interleukin-10 and related cytokines and receptors. Ann Rev Immunol 22: 929-979, 2004. 
18. Sugimoto K, Ogawa A, Mizoguchi E, Shimomura Y, Andoh A, Bhan AK, Blumberg RS, Xavier RJ and Mizoguchi A: IL-22 ameliorates intestinal inflammation in a mouse model of ulcerative colitis. J Clin Invest 118: 534-544, 2008.

19. Honda K: IL-22 from T cells: Better late than never. Immunity 37 : 952-954, 2012

20. Kamanaka M, Huber S, Zenewicz LA, Gagliani N, Rathinam C, O'Connor W Jr, Wan YY, Nakae S, Iwakura Y, Hao L and Flavell RA: Memory/effector (CD45RB(lo)) CD4 T cells are controlled directly by IL-10 and cause IL-22-dependent intestinal pathology. J Exp Med 208: 1027-1040, 2011.

21. Sato T, Vries RG, Snippert HJ, van de Wetering M, Barker N, Stange DE, van Es JH, Abo A, Kujala P, Peters PJ and Clevers H: Single Lgr5 stem cells build crypt-villus structures in vitro without a mesenchymal niche. Nature 459: 262-265, 2009.

22. Sato T, van Es JH, Snippert HJ, Stange DE, Vries RG, van den Born M, Barker N, Shroyer NF, van de Wetering M and Clevers H: Paneth cells constitute the niche for Lgr5 stem cells in intestinal crypts. Nature 469: 415-418, 2011.

23. Dekkers JF, Wiegerinck CL, de Jonge HR, Bronsveld I, Janssens HM, de Winter-de Groot KM, Brandsma AM, de Jong NW, Bijvelds MJ, Scholte BJ, et al: A functional CFTR assay using primary cystic fibrosis intestinal organoids. Nat Med 19: 939-945, 2013

24. Yilmaz ÖH, Katajisto P, Lamming DW, Gültekin Y, Bauer-Rowe KE, Sengupta S, Birsoy K, Dursun A, Yilmaz VO, Selig M, et al: mTORC1 in the Paneth cell niche couples intestinal stem-cell function to calorie intake. Nature 486: 490-495, 2012.

25. Yui S, Nakamura T, Sato T, Nemoto Y, Mizutani T, Zheng X, Ichinose S, Nagaishi T, Okamoto R, Tsuchiya K, et al: Functional engraftment of colon epithelium expanded in vitro from a single adult Lgr5(+) stem cell. Nat Med 18: 618-623, 2012.

26. Sato $\mathrm{T}$ and Clevers $\mathrm{H}$ : Growing self-organizing mini-guts from a single intestinal stem cell: Mechanism and applications. Science 340: 1190-1194, 2013

27. Livak KJ and Schmittgen TD: Analysis of relative gene expression data using real-time quantitative PCR and the 2(-Delta Delta C(T)) method. Methods 25: 402-408, 2001.

28. Pickert G, Neufert C, Leppkes M, Zheng Y, Wittkopf N Warntjen M, Lehr HA, Hirth S, Weigmann B, Wirtz S, et al: STAT3 links IL-22 signaling in intestinal epithelial cells to mucosal wound healing. J Exp Med 206: 1465-1472, 2009.

29. Sonnenberg GF, Fouser LA and Artis D: Border patrol: Regulation of immunity, inflammation and tissue homeostasis at barrier surfaces by IL-22. Nat Immunol 12: 383-390, 2011.

30. Zenewicz LA, Yancopoulos GD, Valenzuela DM, Murphy AJ, Stevens S and Flavell RA: Innate and adaptive interleukin-22 protects mice from inflammatory bowel disease. Immunity 29 : 947-957, 2008

31. Cox JH, Kljavin NM, Ota N, Leonard J, Roose-Girma M, Diehl L, Ouyang W and Ghilardi N: Opposing consequences of IL-23 signaling mediated by innate and adaptive cells in chemically induced colitis in mice. Mucosal Immunol 5: 99-109, 2012.

32. Zheng Y, Valdez PA, Danilenko DM, Hu Y, Sa SM, Gong Q Abbas AR, Modrusan Z, Ghilardi N, de Sauvage FJ and Ouyang W: Interleukin-22 mediates early host defense against attaching and effacing bacterial pathogens. Nat Med 14: 282-289, 2008

33. Basu R, O'Quinn DB, Silberger DJ, Schoeb TR, Fouser L, Ouyang W, Hatton RD and Weaver CT: Th22 cells are an important source of IL-22 for host protection against enteropathogenic bacteria. Immunity 37: 1061-1075, 2012

34. Zenewicz LA, Yin X, Wang G, Elinav E, Hao L, Zhao L and Flavell RA: IL-22 deficiency alters colonic microbiota to be transmissible and colitogenic. J Immunol 190: 5306-5312, 2013.

35. Hanash AM, Dudakov JA, Hua G, O'Connor MH, Young LF, Singer NV, West ML, Jenq RR, Holland AM, Kappel LW, et al: Interleukin-22 protects intestinal stem cells from immune-mediated tissue damage and regulates sensitivity to graft versus host disease. Immunity 37: 339-350, 2012.

36. Muñoz M, Heimesaat MM, Danker K, Struck D, Lohmann U, Plickert R, Bereswill S, Fischer A, Dunay IR, Wolk K, et al: Interleukin (IL)-23 mediates Toxoplasma gondii-induced immunopathology in the gut via matrixmetalloproteinase-2 and IL-22 but independent of IL-17. J Exp Med 206: 3047-3059, 2009.
37. Farin HF, Van Es JH and Clevers H: Redundant sources of Wnt regulate intestinal stem cells and promote formation of Paneth cells. Gastroenterology 143: 1518-1529 e7, 2012.

38. Batlle E, Henderson JT, Beghtel H, van den Born MM, Sancho E, Huls G, Meeldijk J, Robertson J, van de Wetering M, Pawson T and Clevers H: Beta-catenin and TCF mediate cell positioning in the intestinal epithelium by controlling the expression of EphB/ephrinB. Cell 111: 251-263, 2002.

39. Cortina C, Palomo-Ponce S, Iglesias M, Fernández-Masip JL, Vivancos A, Whissell G, Humà M, Peiró N, Gallego L, Jonkheer S, et al: EphB-ephrin-B interactions suppress colorectal cancer progression by compartmentalizing tumor cells. Nat Genet 39: 1376-1383, 2007.

40. Wolk K, Kunz S, Witte E, Friedrich M, Asadullah K and Sabat R: IL-22 increases the innate immunity of tissues. Immunity 21 : 241-254, 2004.

41. Raffatellu M, George MD, Akiyama Y, Hornsby MJ, Nuccio SP, Paixao TA, Butler BP, Chu H, Santos RL, Berger T, et al: Lipocalin-2 resistance confers an advantage to Salmonella enterica serotype Typhimurium for growth and survival in the inflamed intestine. Cell Host Microbe 5: 476-486, 2009.

42. Chung Y, Yang X, Chang SH, Ma L, Tian Q and Dong C: Expression and regulation of IL-22 in the IL-17-producing $\mathrm{CD}^{+}{ }^{+} \mathrm{T}$ lymphocytes. Cell Res 16: 902-907, 2006.

43. Liang SC,TanXY,LuxenbergDP,KarimR,Dunussi-JoannopoulosK, Collins M and Fouser LA: Interleukin (IL)-22 and IL-17 are coexpressed by Th17 cells and cooperatively enhance expression of antimicrobial peptides. J Exp Med 203: 2271-2279, 2006.

44. Zheng Y,Danilenko DM, ValdezP,Kasman I,Eastham-Anderson J, Wu J and Ouyang W: Interleukin-22, a T(H)17 cytokine, mediates IL-23-induced dermal inflammation and acanthosis. Nature 445: 648-651, 2007.

45. Yan KS, Janda CY, Chang J, Zheng GXY, Larkin KA, Luca VC, Chia LA, Mah AT, Han A, Terry JM, et al: Non-equivalence of Wht and R-spondin ligands during Lgr $5^{+}$intestinal stem-cell self-renewal. Nature 545: 238-242, 2007.

46. Lindemans CA, Calafiore $M$, Mertelsmann AM, O'Connor MH, Dudakov JA, Jenq RR, Velardi E, Young LF, Smith OM, Lawrence $\mathrm{G}$, et al: Interleukin-22 promotes intestinal-stem-cell-mediated epithelial regeneration. Nature 528: $560-564,2015$

47. Andoh A, Zhang Z, Inatomi O, Fujino S, Deguchi Y, Araki Y, Tsujikawa T, Kitoh K, Kim-Mitsuyama S, Takayanagi A, et al: Interleukin-22, a member of the IL-10 subfamily, induces inflammatory responses in colonic subepithelial myofibroblasts. Gastroenterology 129: 969-984, 2005.

48. Dumoutier L, Leemans C, Lejeune D, Kotenko SV and Renauld JC: Cutting edge: STAT activation by IL-19, IL-20 and mda-7 through IL-20 receptor complexes of two types. J Immunol 167: 3545-3549, 2001.

49. Sabat R: IL-10 family of cytokines. Cytokine Growth Factor Rev 21: 315-324, 2010.

50. Wang M, Tan Z,Zhang R, Kotenko SV and Liang P: Interleukin 24 (MDA-7/MOB-5) signals through two heterodimeric receptors, IL-22R1/IL-20R2 and IL-20R1/IL-20R2. J Biol Chem 277: 7341-7347, 2002.

51. Li LJ, Gong C, Zhao MH and Feng BS: Role of interleukin-22 in inflammatory bowel disease. World J Gastroenterol 20: 18177-18188, 2014.

52. Sugimoto S, Naganuma M, Kiyohara H, Arai M, Ono K, Mori K, Saigusa K, Nanki K, Takeshita K, Takeshita T, et al: Clinical efficacy and safety of oral Qing-Dai in patients with ulcerative colitis: A single-center open-label prospective study. Digestion 93: 193-201, 2016.

53. Low D, Mino-Kenudson M and Mizoguchi E: Recent advancement in understanding colitis-associated tumorigenesis. Inflamm Bowel Dis 20: 2115-2123, 2014.

This work is licensed under a Creative Commons Attribution-NonCommercial-NoDerivatives 4.0 International (CC BY-NC-ND 4.0) License. 